\title{
DIAGNOSA BUTA WARNA DENGAN METODE ISHIHARA TERHADAP SISWA SMPN 1 BUNGORO KABUPATEN PANGKEP
}

\author{
Ryan Humardani Syam Pratomo ${ }^{1}$, Sri Mukminati Nur ${ }^{2}$, Erni Rismawanti $^{3}$, Nina Wahyuni ${ }^{4}$ \\ ${ }^{1,2,4)}$ Program Studi Pendidikan Biologi, STKIP Pembangunan Indonesia \\ ${ }^{3)}$ Prodi Pendidikan Ekonomi, STKIP Pembangunan Indonesia \\ e-mail: ryanhumardani01@gmail.com
}

\begin{abstract}
Abstrak
Pengabdian ini dilaksanakan di SMPN 1 Bungoro yang terletak di Kabupaten Pangkep Sulawesi Selatan. Permasalahan mitra yaitu siswa SMPN 1 Bungoro Kabupaten Pangkep belum mengetahui dan memahami tentang kelainan buta warna dan siswa juga tidak mengetahui apakah penglihatan mereka normal ataukah mereka mengalami kelainan buta warna. Alternatif solusi masalah yaitu memberikan pengetahuan kepada siswa tentang kelainana buta warna dan melakukan tes buta warna dengan metode Ishihara kepada siswa SMPN 1 Bungoro Kabupaten Pangkep. Adapun target luaran yang ingin dicapai yaitu meningkatnya pengetahuan siswa SMPN 1 Bungoro Kabupaten Pangkep tentang kelainan buta warna dan siswa-siswi SMPN 1 Bungoro Kabupaten Pangkep sudah mengetahui diri mereka apakah menderita kelainan buta warna atau tidak. Metode yang akan dilakukan yaitu presentasi tentang kelainan buta warna dan melakukan tes buta warna kepada siswa SMPN 1 Bungoro Kabupaten Pangkep dengan menggunakan buku Ishihara yang berisi 24 plate. Dari hasil kegiatan yang telah dilakukan diperoleh hasil semua siswa SMPN 1 Bungoro Kabupaten Pangkep yang telah melakukan tes buta warna sudah memahami tentang kelainan buta warna dan $100 \%$ siswa tidak mengalami buta warna (mata normal).
\end{abstract}

Kata Kunci: Diagnosa, Buta Warna, Metode Ishihara

\begin{abstract}
This service activity was carried out at SMPN 1 Bungoro located in Pangkep Regency, South Sulawesi. The parnert problem is that students of SMPN 1 Bungoro, do not know and understand about color blindness and students also do not know whether they have color blindness. Alternative solutions to the problem are providing knowledge to students about color blindness and conducting a color blind test using the Ishihara method to student of SMPN 1 Bungoro, Pangkep Regency. As for the output target to be achieved, namely the increased knowledge of students of SMPN 1 Bungoro Pangkep regency about color blindness disorder and students of SMPN 1 Bungoro in Pangkep Regency already know whether they are suffering from color blindness or not. The method to be carried out is a presentation on color blindness disorders and a color blind test for students of SMPN 1 Bungoro Pangkep Regency by using the Ishihara book containing 24 plates. From the results of the activities that have been carried out, it was found that all students of SMPN 1 Bungoro Pangkep Regency who have done a color blind test already understand about color blindness and $100 \%$ of students do not experience color blindness (normal eyes).
\end{abstract}

Keywords: Diagnosis, Color Blindness, Ishihara Method

\section{PENDAHULUAN}

Salah satu gangguan yang terjadi pada mata adalah buta warna. Buta warna adalah suatu keadaan dimana seseorang tidak dapat membedakan warna tertentu yang bisa dibedakan oleh orang dengan mata normal. Buta warna merupakan kekurangan penglihatan atas warna. Mata tidak akan melihat warna seperti biasanya jika ada masalah dengan pigmen pada reseptor mata (Utami, 2015).

Seseorang yang menderita buta warna dapat disebabkan oleh kelainan sejak lahir atau akibat penggunaan obat-obatan yang berlebihan. Secara anatomi, sel saraf pada retina terdiri atas sel batang yang peka terhadap hitam dan putih, serta sel kerucut yang peka terhadap warna lainnya. Buta warna terjadi ketika saraf reseptor cahaya di retina mengalami perubahan, terutama sel kerucut. Penglihatan bergantung pada stimulasi fotoreseptor retina oleh cahaya. Sesorang bisa melihat suatu benda karena cahaya yang mengenai benda tersebut tidak semua diserap oleh benda 
tersebut, cahaya yang tidak diserap dipantulkan. Cahaya yang dipantulkan inilah yang dapat kita lihat. Apabila suatu benda kita lihat berwarna biru, artinya benda tersebut menyerap panjang gelombang cahaya merah dan hijau dan memantulkan panjang gelombang biru, panjang gelombang biru inilah yang diserap oleh fotopigmen di sel-sel kerucut biru mata, sehingga terjadi pengaktifan sel-sel tersebut dan akhirnya kita bias melihat bahwa benda tersebut berwarna biru (Yanuarita, 2012).

Warna primer yaitu warna dasar yang dapat memberikan jenis warna yang terlihat dengan campuran ukuran tertentu. Pada sel kerucut terdapat 3 macam pigmen yang dapat membedakan warna dasar merah, hijau dan biru. Sel kerucut yang menyerap long-wavelenght light (red), sel kerucut yang menyerap middle-wavelenght light (green), sel keucut yang menyerap shortwavelenght light (blue) (Rokhim, 2015).

Buta warna sering menjadi masalah saat seseorang harus memilih jurusan dalam jenjang pendidikan, khususnya untuk pekerjaan yang membutuhkan pengkodean warna dalam pekerjaan seperti dokter, polisi, masinis dan lain-lain (Rokhim, 2015).

Banyak anak-anak bangsa yang memiliki cita-cita tinggi harus kandas di tengah jalan hanya karena mereka menderita buta warna. Misalnya ingin menjadi Polisi maupun profesi lainnya yang membutuhkan syarat surat kesehatan yang didalamnya terdapat syarat cek buta warna. Untuk meminimalisir terjadinya hal demikian, seharusnya pemerintah memfokuskan masalah ini dengan melakukan tes buta warna sedini mungkin, sehingga diharapkan anak yang menderita buta warna sudah mengetahui keadaan dirinya dan tidak menggantungkan cita-cita setinggi langit yang tidak memungkinkan menerima penderita buta warna.

Dengan demikian anak penderita buta warna bisa mengalihkan dan mengembangkan bakatnya ke bakat lain yang memungkinkan bagi si anak dengan kelainan buta warna. Tes buta warna bisa dilakukan terhadap anak mulai sejak SMP kelas 1 ke atas. Karena anak usia kelas 1 SMP ke atas sudah bisa memahami warna dan angka, sehingga memudahkan dalam melakukan tes buta warna. Tes buta warna yang paling mudah dan sering dilakukan adalah tes buta warna metode Ishihara.

Berdasarkan dari hasil observasi, di SMPN 1 Bungoro Kabupaten Pangkep belum pernah diadakan tes buta warna sebelumnya, hal ini yang mendasari kami untuk melakukan kegiatan pengabdian dengan judul "Diagnosa Tes Buta Warna Dengan Metode Ishihara terhadap Siswa SMPN 1 Bungoro Kabupaten Pangkep". Dengan berdasarkan hasil observasi di SMPN 1 Bungoro Kabupaten Pangkep maka permasalahan mitra yaitu siswa SMPN 1 Bungoro Kabupaten Pangkep belum mengetahui dan memahami tentang kelainan buta warna dan siswa SMPN 1 Bungoro Kabupaten Pangkep tidak mengetahui apakah penglihatan mereka normal ataukah mereka mengalami kelainan buta warna.

Adapun penelitian terdahulu yang relevan merupakan hal yang sangat penting untuk dijadikan rujukan basis data pendukung dalam melaksanakan pengabdian kepada masyarat ini karena memiliki acuan yang merupakan teori dan hasil penelitian. Penelitian sebelumnya tentang tes buta warna pernah dilakukan oleh dari Dhika dkk (2014), dalam penelitiannya yang berjudul Tes buta warna dengan metode Ishihara pada smartphone Android. Dimana penelitiannya seseorang dapat melakukan tes buta warna dengan menggunakan smartphone android.

Penelitian yang lain telah dilakukan oleh Andri Umbari (2017) yang berjudul Penerapan metode Ishihara untuk mendeteksi buta warna sejak dini berbasis android. Dalam penelitiannya ia berhasil menghasilkan sistem pengujian jenis buta warna metode Ishihara pada smartphone android yang dapat digunakan oleh pengguna untuk mendeteksi buta warna secara dini dengan tampian dan navigasi yang user friendly dengan hasil tes yang dapat diketahui secara langsung yang dibangun dengan menggunakan Java For Android dan IDE Android Studio 2.2.3.

\section{METODE}

Metode pelaksanaan pengabdian ini dengan metode pendidikan masyarakat. Metode pendidikan masyarakat merupakan penyuluhan yang bertujuan meningkatkan pemahaman serta kesadaran akan pentingnya kegiatan pengabdian ini. Pada metode ini dilaksanakan dengan dua cara yaitu pemberian materi dan melakukan tes buta warna menggunakan metode ishihara.

1. Pemberian Materi 
a. Memberikan penjelasan mengenai kelainan buta warna dan macam-macam buta warna melalui presentasi dengan menggunakan LCD dan powerpoint

b. Menjelaskan faktor penyebab buta warna

c. Menjelaskan tentang pentingnya melakukan tes buta warna sedini mungkin pada anak-anak

d. Menjelaskan alternatif untuk pencegahan dan mengatasi kelainan buta warna.

2. Melalukan Tes Buta Warna Menggunakan Metode Ishihara

a. Metode Ishihara yang digunakan adalah Ishihara 24 plate. Plate merupakan lembaran pseudoisokromatik yang disusun oleh titik-titik dengan kepadatan warna berbeda. Dimana setiap plate terdapat titik warna yang membentuk lingkaran dan didalamnya terdapat angka yang harus ditebak oleh siswa

b. Metode Ishihara dilakukan dengan cara menggilir satu persatu siswa. Setiap siswa yang mendapat giliran, dipersilahkan maju ke depan. Siswa mengisi daftar peserta setelah itu dilakukan tes.

c. Plate atau lembaran ditampilkan satu persatu, dengan jedah waktu 10 detik untuk memberikan waktu kepada siswa dalam mengamati angka didalam plate. Setelah 10 detik plate akan dipindahkan ke plate berikutnya dan siswa menjawab angka yang telah mereka amati. Kami menulis jawaban yang telah disebutkan oleh siswa.

d. Setelah semua plate disajikan, pemateri akan membahas jawaban yang benar dari setiap plate, dan mencocokkan semua jawaban dari siswa, sehingga pada akhirnya akan diketahui siswa yang normal, buta warna sebagian, dan buta warna total.

\section{HASIL DAN PEMBAHASAN}

Pelaksanaan PKM Diagnosa Buta Warna dengan Metode Ishihara di SMPN 1 Bungoro Kabupaten Pangkep berjalan dengan baik. Kegiatan ini dilaksanakan pada hari Sabtu, 16 November 2020 di SMPN 1 Bungoro Kabupaten Pangkep. Kegiatan ini diawali dengan presentasi kelainan buta warna, penyebab buta warna, macam-macam buta warna, dan metode Ishihara. Dilanjutkan dengan tes buta warna dengan menggunakan buku tes buta warna yang terdiri atas 24 plate.

Pada Tes ishihara persepsi penglihatan pada anak-anak akan berbeda antara anak yang normal, anak yang mengalami buta warna sebagian, dan buta warna total. Perbedaan penglihatan anak disajikan dalam tabel 1 berikut:

Tabel 1. Tes Ishihara,normal, buta warna sebagian (hijau-merah) dan buta warna total.

\begin{tabular}{|c|c|c|c|}
\hline Plate & Normal & $\begin{array}{c}\text { Buta warna } \\
\text { sebagian (Parsial) }\end{array}$ & $\begin{array}{c}\text { Buta warna } \\
\text { total }\end{array}$ \\
\hline 1 & 12 & 12 & 12 \\
\hline 2 & 8 & 3 & $\mathrm{X}$ \\
\hline 3 & 29 & 70 & $\mathrm{X}$ \\
\hline 4 & 5 & 2 & $\mathrm{X}$ \\
\hline 5 & 3 & 5 & $\mathrm{X}$ \\
\hline 6 & 15 & 17 & $\mathrm{X}$ \\
\hline 7 & 74 & 21 & $\mathrm{X}$ \\
\hline 8 & 6 & $\mathrm{X}$ & $\mathrm{X}$ \\
\hline 9 & 45 & $\mathrm{X}$ & $\mathrm{X}$ \\
\hline 10 & 5 & $\mathrm{X}$ & $\mathrm{X}$ \\
\hline 11 & 7 & $\mathrm{X}$ & $\mathrm{X}$ \\
\hline 12 & 16 & $\mathrm{X}$ & $\mathrm{X}$ \\
\hline 13 & 73 & 5 & $\mathrm{X}$ \\
\hline 14 & $\mathrm{X}$ & 45 & $\mathrm{X}$ \\
\hline 15 & $\mathrm{X}$ & $6 / 2$ & \\
\hline 16 & 26 & $2 / 4$ & \\
\hline 17 & 42 & & \\
\hline
\end{tabular}




\begin{tabular}{|c|c|c|c|}
\hline 18 & $\begin{array}{c}\text { Garis Ungu- } \\
\text { merah }\end{array}$ & Garis Ungu & $\mathrm{X}$ \\
\hline 19 & $\mathrm{X}$ & Ada garis & $\mathrm{X}$ \\
\hline 20 & $\begin{array}{c}\text { Garis hijau } \\
\text { kebiruan }\end{array}$ & $\mathrm{X}$ & $\mathrm{X}$ \\
\hline 21 & Orange & $\mathrm{X}$ & $\mathrm{X}$ \\
\hline 22 & $\begin{array}{c}\text { Hijau } \\
\text { keebiruan/hijau } \\
\text { kekuningan }\end{array}$ & Garis Hijau-ungu & $\mathrm{X}$ \\
\hline 23 & $\begin{array}{c}\text { Garis Ungu- } \\
\text { orange }\end{array}$ & Ungu-hijau & $\mathrm{X}$ \\
\hline 24 & Orange & & \\
\hline
\end{tabular}

(Sumber: Ishihara,Sinobu dan diadaptasi oleh penulis)

Keterangan: $\mathrm{X}=$ tidak dapat dibaca.

Analisis hasil tes ishihara yaitu jika 13 atau lebih plate dibaca benar, artinya mata normal tidak mengalami kelainan buta warna. Jika hanya 9 atau kurang dari 9 plate dibaca benar, artinya mengalami buta wana sebagian. Jika hanya plate 1 yang bias dibaca benar,artinya mengalami kelainan buta warna.

Berikut contoh 24 plate yang kami pakai dalam mendiagnosis peserta didik/siswa di SMPN 1 Bungoro Kabupaten Pangkep

Tabel 2. Plate Tes Buta Warna dengan Metode Ishihara

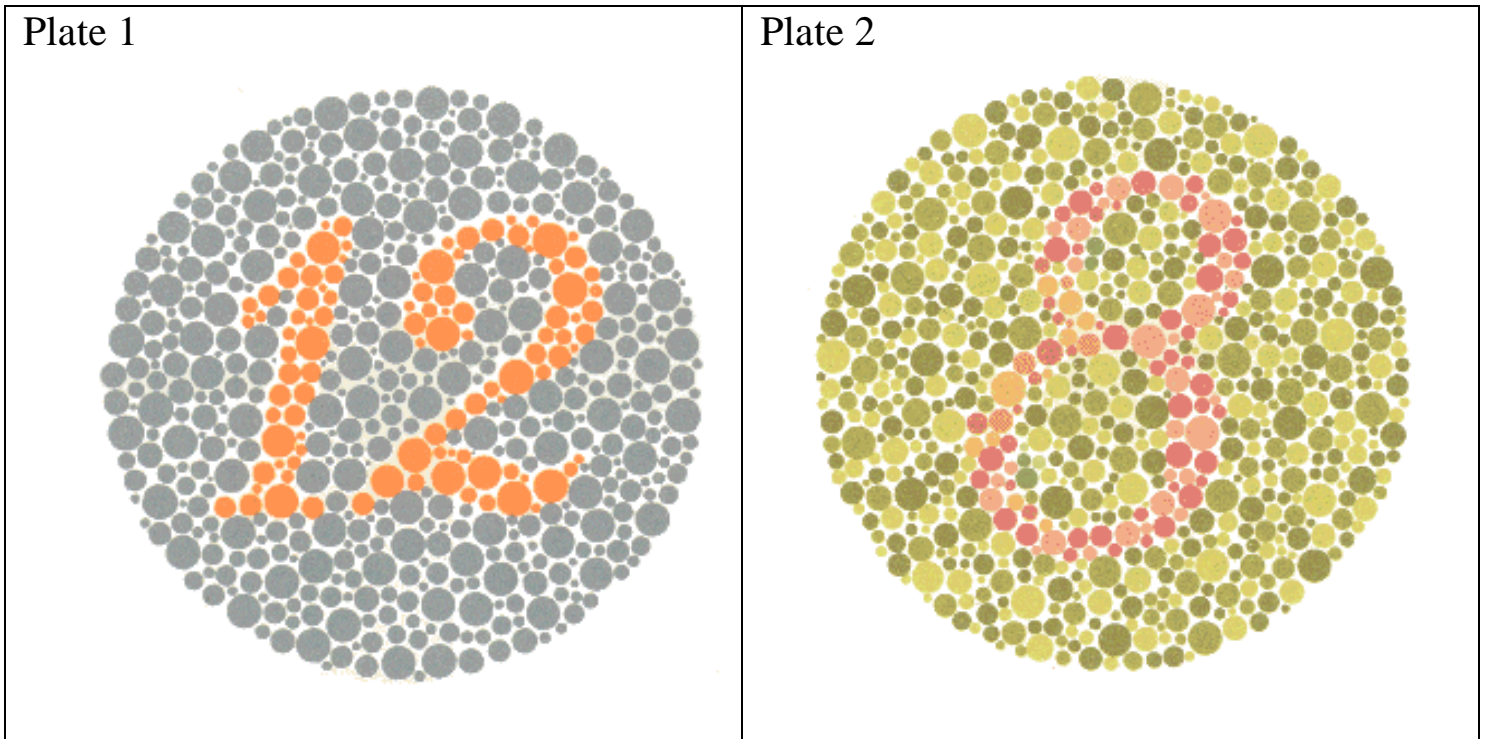




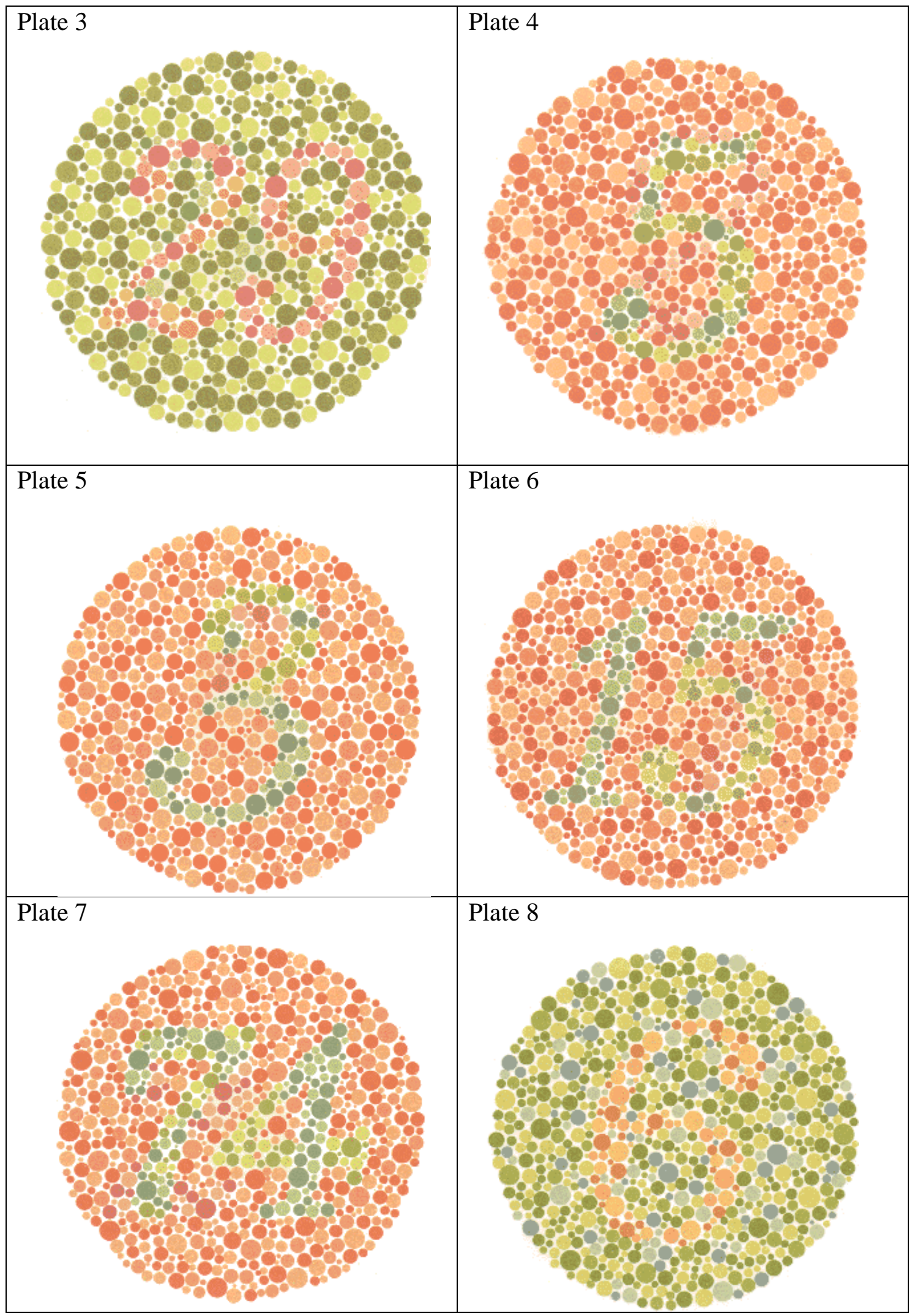




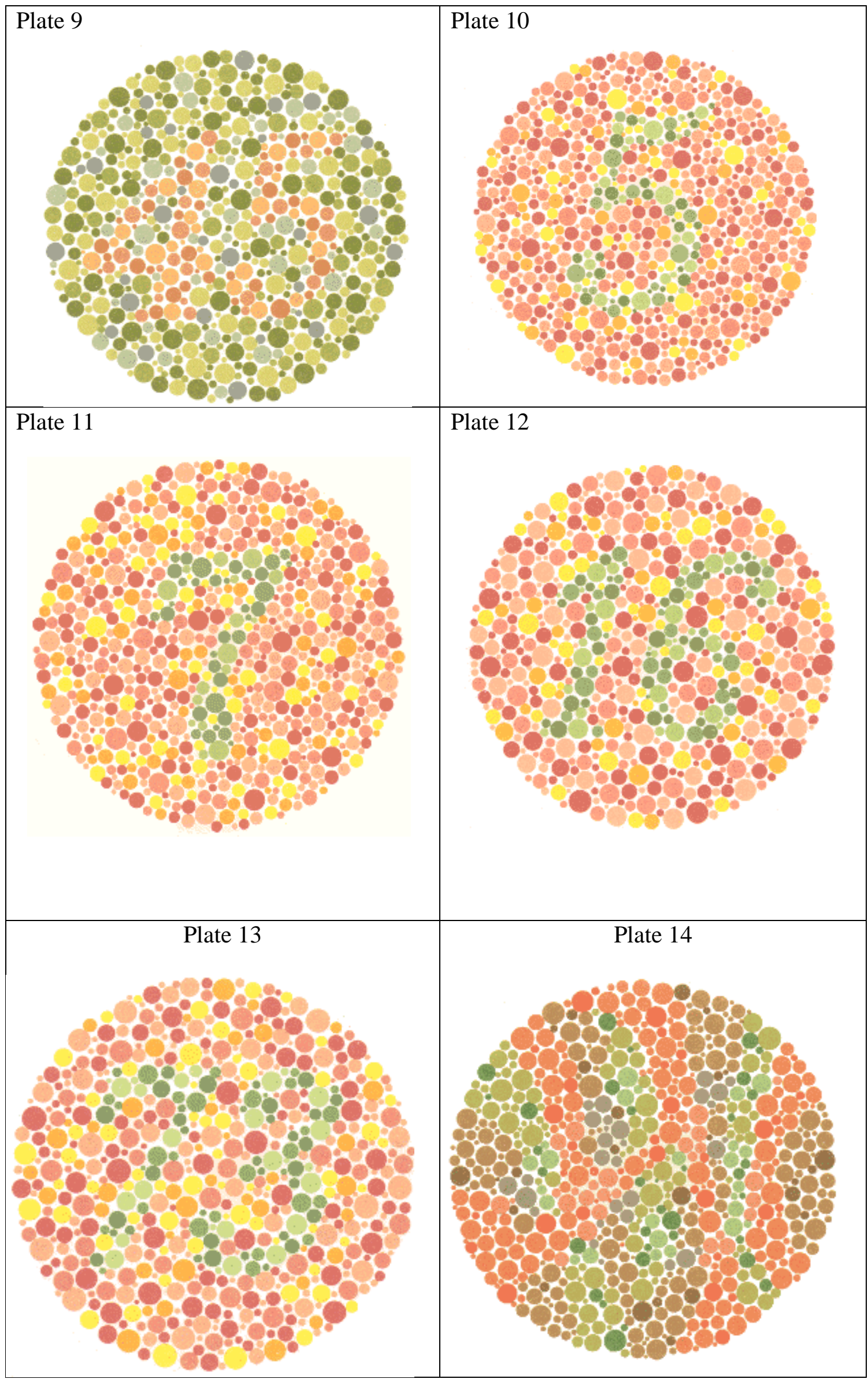




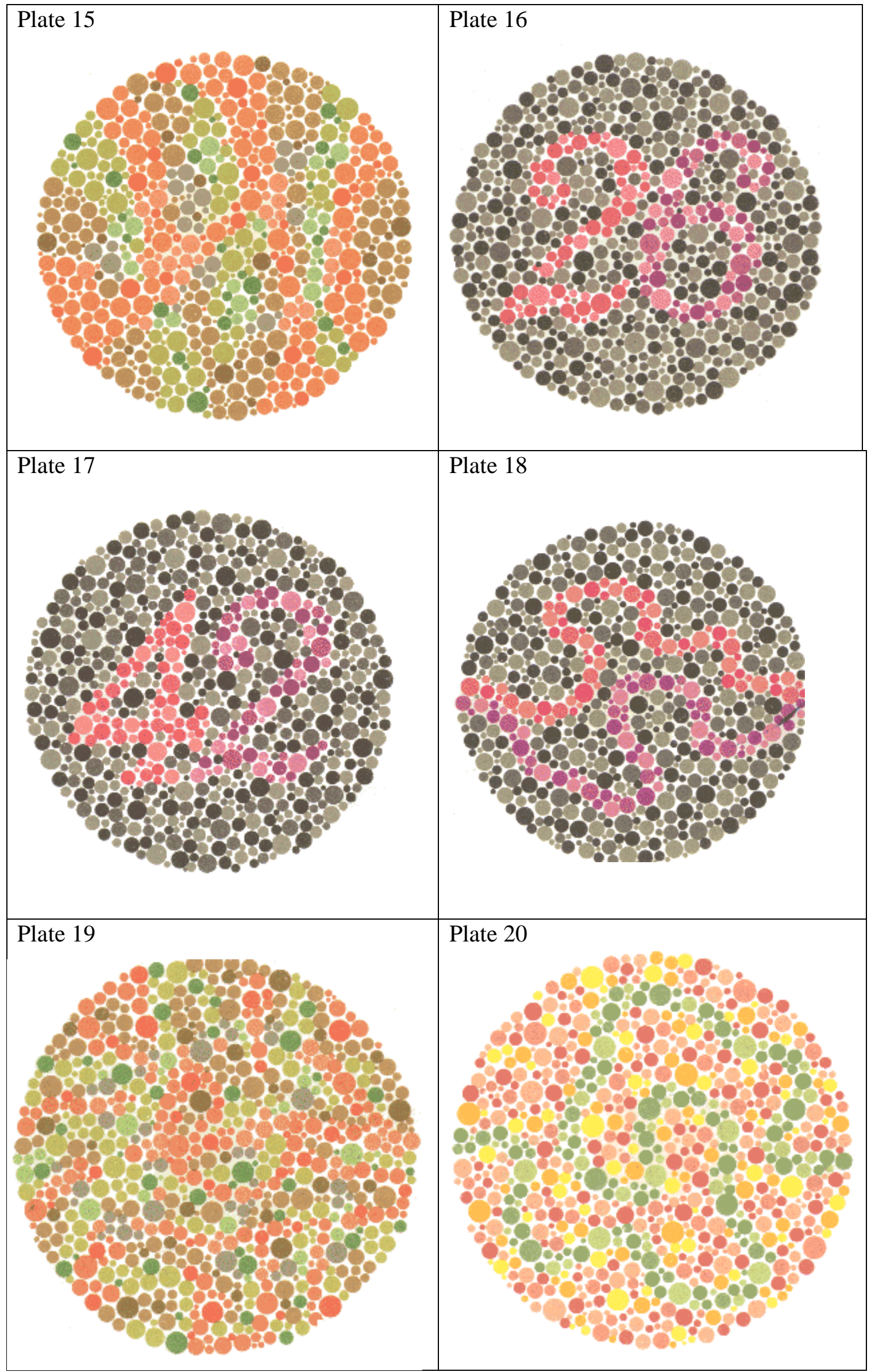




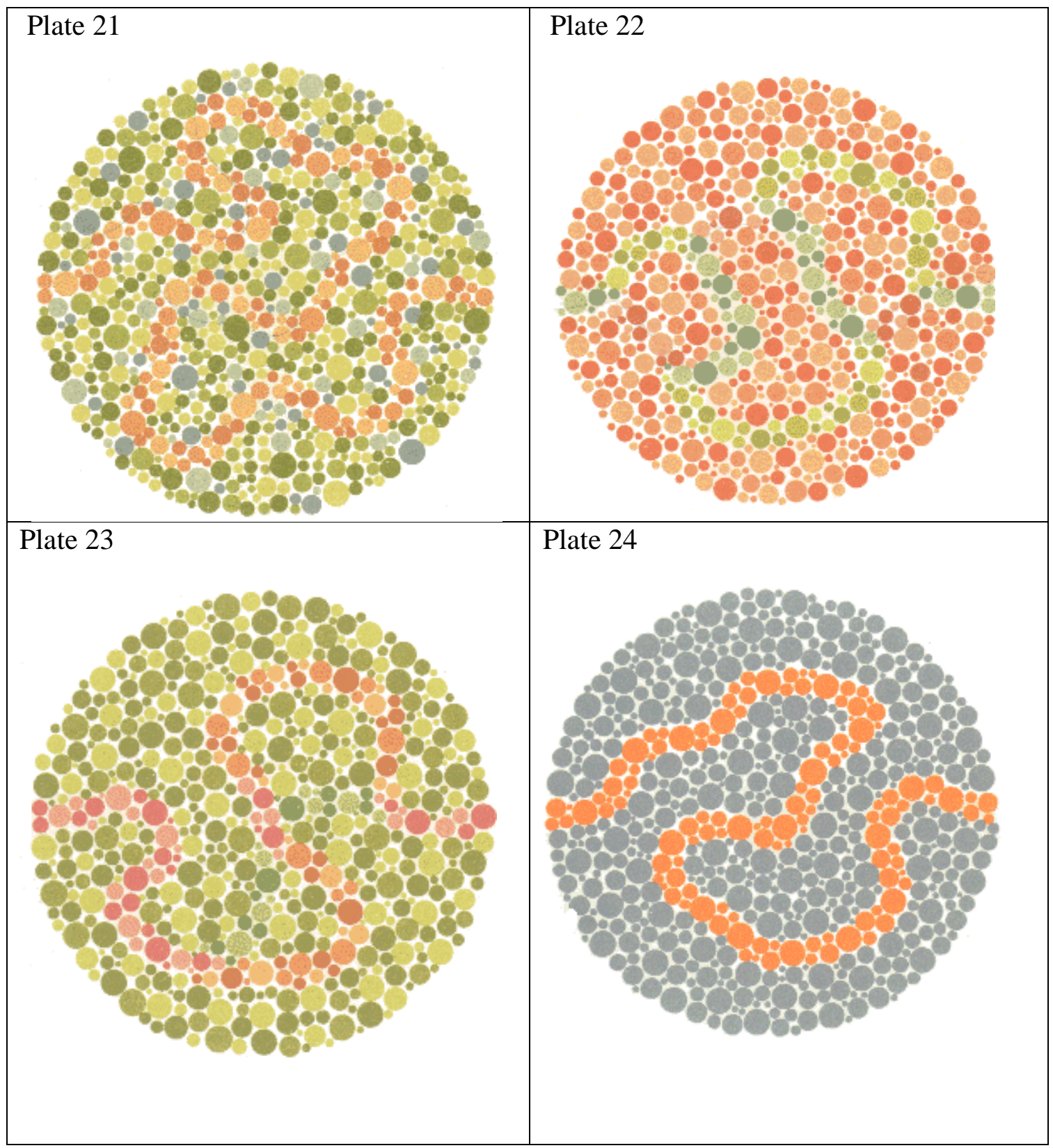

Hasil kegiatan tes buta warna pada siswa SMPN 1 Bungoro Kabupaten Pangkep disajikan dalam tabel 2.dibawah ini:

Tabel 3. Hasil Tes Buta Warna dengan Metode Ishihara di SMPN 1 Bungoro Kabupaten Pangkep

\begin{tabular}{|c|l|c|c|}
\hline No & \multicolumn{1}{|c|}{ Nama } & Jawaban benar & Hasil tes \\
\hline 1 & Muh.Azhar & 21 & Normal \\
\hline 2 & Nurjannah & 23 & Normal \\
\hline 3 & Mustamin & 23 & Normal \\
\hline 4 & Sri Reski & 20 & Normal \\
\hline 5 & Sri Muslimat & 22 & Normal \\
\hline 6 & Syahrul & 24 & Normal \\
\hline 7 & Rifqah Amani & 20 & Normal \\
\hline 8 & Dewi Pertiwi & 20 & Normal \\
\hline
\end{tabular}




\begin{tabular}{|c|l|c|l|}
\hline 9 & Fadli dzahir & 22 & Normal \\
\hline 10 & Syamsul & 23 & Normal \\
\hline 11 & Rahmadani Sanur & 24 & Normal \\
\hline 12 & Megawati & 24 & Normal \\
\hline 13 & Markus & 24 & Normal \\
\hline 14 & Sumarni & 21 & Normal \\
\hline 15 & Tajuddin & 22 & Normal \\
\hline 16 & Nisfi Syahban & 24 & Normal \\
\hline 17 & Mudzakkir & 24 & Normal \\
\hline 18 & Arwin & 22 & Normal \\
\hline 19 & Fandi Abdullah & 21 & Normal \\
\hline 20 & Syukriani & 23 & Normal \\
\hline 21 & Ahmad Junaidi & 21 & Normal \\
\hline 22 & Sulfaidah & 20 & Normal \\
\hline 23 & Zulfitrah & 24 & Normal \\
\hline 24 & Sofia & 22 & Normal \\
\hline 25 & Abdul Rahim & 21 & Normal \\
\hline
\end{tabular}

Berdasarkan hasil tes buta warna pada tabel 3, semua siswa yang dites mendapatkan jawaban benar lebih dari 13 plate, hal ini berarti bahwa semua siswa tidak mengalami kelainan buta warna atau semua siswa normal. Siswa yang memperoleh jawaban benar kurang dari 24 , pada umumnya mengalami kendala pada plate 13 dan 1plate 18 keatas. Pada plate 13 berisi angka 73, tetapi kebanyakan siswa menjawab 78.

Pada plate ini siswa terkecoh antara angka 3 dengan angka 8, yang hanya memiliki perbedaan sangat tipis. Sedangkan pada plate 18 ke atas sampai ke plate 24 berisi garis bukan angka. Garis ini terdiri dari gradasi warna tua sampai muda, sehingga siswa seumuran anak SMP masih susah membedakannya, yang seharusnya jawaban benar warna hijau muda, siswa hanya menjawab warna hijau.

\section{SIMPULAN}

Berdasarkan kegiatan pengabdian kepada masyarakat yang kami lakukan dapat disimpulkan bahwa kegiatan presentasi materi buta warna telah meningkatkan pengetahuan dan pemahaman siswa tentang kelainan buta warna, melalui diagnosa tes buta warna dengan metode Ishihara, siswa dapat mengetahui bahwa mereka mengalami buta warna atau tidak, semua siswa yang melakuka tes buta warna sebanyak 25 orang dinyatakan memiliki penglihatan yang normal atau tidak mengalami buta warna.

\section{SARAN}

Berdasarkan dari hasil kegiatan pengabdian kepada masyarakat ini, kami mengajukan beberapa saran yaitu melakukan diagnosa tes buta warna untuk semua siswa di SMPN 1 Bungoro Kabupaten Pangkep dan sekolah lainnya agar kelainan buta warna dapat diantisipasi sejak dini, agar hasil tes buta warna lebih maksimal, perlu diadakan tes buta warna metode Ishihara berbasis teknologi android.

\section{UCAPAN TERIMA KASIH}

Penulis mengucapkan terima kasih kepada Kepala Sekolah, Guru-Guru dan Siswa atas kesediaannya membolehkan kami melakukan pengabdian kepada masyarakat di SMPN 1 Bungoro Kabupaten Pangkep. 


\section{DAFTAR PUSTAKA}

Andi, Umbari., \& Alvino Octaviano, D. (2017). Penerapan Metode Ishihara Untuk Mendeteksi Buta Warna Sejak Dini Berbasis Android. Jurnal Informatika Universitas Pamulang. Volume 2 Nomor 1 Maret 2017, ISSN 2541-1004

Dhika, R.V., Ernawati., \& Andreswari, D. (2014). Aplikasi Tes Buta Warna Dengan Metode Ishihara Pada Smartphone Android. Jurnal Pseudocode. Volume 1 Nomor 1 Februari 2014, ISSN 2355-5920

Rokhim, A.N, S. (2015). Mengenal Tes Buta Warna. Surabaya: CV. Berkah Utami.

Shinobu Ishihara. 1972. Test For Colour-blindness. Online diakses tanggal 10 November 2020. https://www.truecourses.com/documents/Forms/IshiharaTestPlates.pdf

Utami, S. (2015). Seluk Beluk Buta Warna. Yogyakarta: Pustaka Baru Press.

Yanuarita, Andi. (2012). Tes Buta Warna. Yogyakarta: Rona Publishing. 